\title{
Risk of Impingement on Polyethylene Liner of Total Hip Arthroplasty Prosthesis during Muslim Prayer (Salat) Activity
}

\author{
Iwan Budiwan Anwar ${ }^{1,2 *}$, Eko Saputra $^{1,3}$, Rifky Ismail $^{3}$, J. Jamari $^{3}$, Emile van der Heide $^{1}$ \\ ${ }^{1}$ Laboratory for Surface Technology and Tribology, Faculty of Engineering Technology, University of Twente, Drienerlolaan 5 , \\ Postbox 217, 7500 AE, Enschede, The Netherlands; ${ }^{2}$ Department of Orthopaedic and Traumatology, Prof. Dr. R. Soeharso \\ Orthopaedic Hospital, Sebelas Maret University, Jl. A. Yani Pabelan, Surakarta 57162, Indonesia; ${ }^{3}$ Department of Mechanical \\ Engineering, Laboratory for Engineering Design and Tribology, Diponegoro University, Jl. Prof. Soedarto, Tembalang, Semarang \\ 50275, Indonesia
}

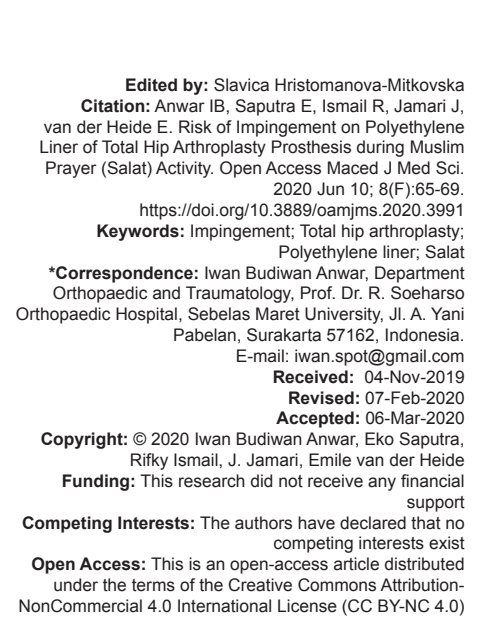

Introduction

Total hip arthroplasty (THA) is one of the most successful orthopedic surgical procedures. Patient could obtain early return to ambulation and experienced considerable relieve of pain after the operation. However, dislocation remains known as one of the difficult problems following THA [1]. It could occur at around $2 \%$ of primary THA and increased to around $5 \%$ of cases in revision THA [2]. Several factors such as impingement, implant malposition, surgical approach, femoral head size, and lack of softtissue tension known as risk factors for dislocation after THA [3], [4], [5]. Although not all impingement associated with dislocation, still impingement believed to be the most common mechanism of dislocation after THA [3].

Salat (prayer) is one of the " 5 pillars" of Islam (Table 1) [6]. A Muslim (people who practice the religion of Islam) has to do salat on a daily basis. Salat consist of several repeated physical movement
Table 1: The "5 pillars" of Islam [6]

\begin{tabular}{ll}
\hline Arabic term & English term \\
\hline Shahada & Declaration of belief \\
Salat & Prayers \\
Zakat & Charity \\
Sawm & Fasting \\
Hajj & Pilgrimage \\
\hline
\end{tabular}

which require several extreme hip joint movement. This short review aimed to discuss the possibility of impingement occurred to the polyethylene (PE) liner of THA prosthesis associated with salat activity.

\section{Prosthesis Impingement}

THA prosthesis impingement occurred when there is a repetitive direct contact of acetabular cup/ liner to the femoral neck component during the range of motion of the joint [7] (Figure 1). Impingement could cause poor outcomes of hip arthroplasty due to instability, 


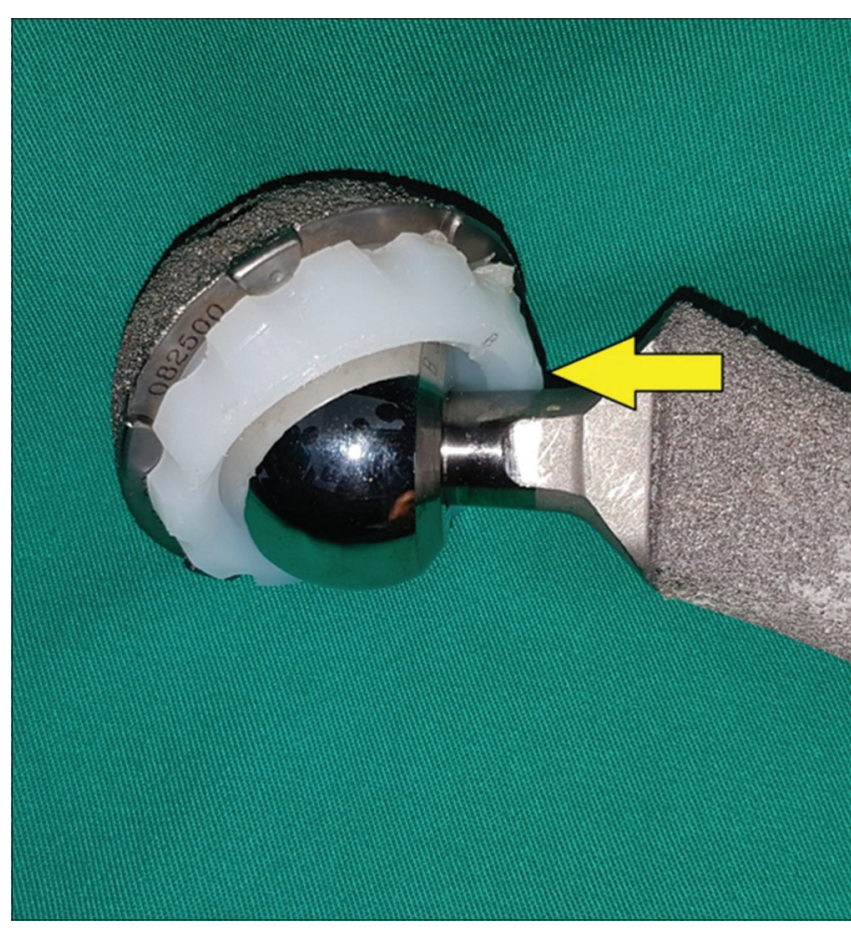

Figure 1: Site of impingement indicated by the arrow.

accelerated wear, and unexplained pain [8]. A large THA retrieval study from Western country showed that the prosthesis impingement rate could occur at as high as $50 \%$ of cases [9]. Impingement could cause PE liner damage. Muealler et al. [10] described three types of PE liner damage: Collar fatigue, rim creep, and backside wear. Collar fatigue defined as deformation and fatigue at the collar of the PE inlay in the area where the collar (outer rim) is in contact with the acetabular shell. Rim creep defined as deformation at the inner rim of the PE inlay leading to narrowing at the cup opening (Figure 2a), while backside wear defined as wear at the back of the PE liner (Figure 2b). Another author, French et al. [11] described the PE damage based on the presence of cracking/fracture into three categories based on their study to 129 retrieved Harris-Galante ${ }^{\circledR}$ PE liner: Type I (subsurface cracking), Type II (incomplete rim fracture), and Type III (complete rim fracture). Further, Marchetti et al. [9] classified the polyethylene impingement into four grades (Table 2). Their $416 \mathrm{PE}$ liner retrieval study showed that the most common impingement occurred at Grade 1 and 2 by $20 \%$ and $19 \%$, respectively.

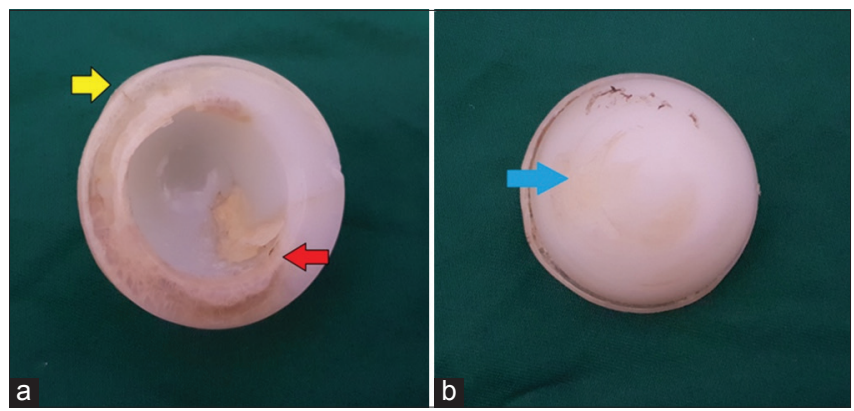

Figure 2: (a) Rim Creep (Red arrow) and Collar fatique (Yellow arrow) indicate in this retrieved PE Liner, (b) Backside wear indicate by the blue arrow. (Source: Author personal collection)
Table 2: Classification of acetabular polyethylene liner impingement according to Marchetti et al. [9]

\begin{tabular}{ll}
\hline Impingement & Acetabular ring aspect \\
\hline Grade 0 & No ring or visible abrasion at equator \\
Grade 1 & Notch visible at equator, but $\leq 1 \mathrm{~mm}$ \\
Grade 2 & Notch $>1 \mathrm{~mm} \leq 3 \mathrm{~mm}$ \\
Grade 3 & Notch $>3 \mathrm{~mm}$ \\
\hline
\end{tabular}

Our preliminary data from 10 retrieved acetabular liners are shown in Table 3 [12]. All PE liners were retrieved from revision THA surgery. Five of 10 (50\%) PE liners were experienced impingement.

Table 3: Short analysis from the retrieved polyethylene liner from our 10 revision total hip arthroplasty cases

\begin{tabular}{|c|c|c|}
\hline No. & Variables & Results (n: 10) \\
\hline \multirow[t]{3}{*}{1} & Classification PE liner according to Tanino et al. [12] & Type A: 9 \\
\hline & & Type B: 0 \\
\hline & & Type C: 1 \\
\hline \multirow[t]{2}{*}{2} & Standard/Elevated rim (Figure $4 a$ and $b$ ) & Standard : 6 \\
\hline & & Elevated: 4 \\
\hline \multirow[t]{2}{*}{3} & Impingement site (Occurred at 5 of $10 \mathrm{PE}$ liner $^{\star}$ ) & At elevated part: 2 \\
\hline & & At non-elevated part: 5 \\
\hline \multirow[t]{2}{*}{4} & Backside wear (Yes/No) & Yes: 5 \\
\hline & & No: 5 \\
\hline \multirow[t]{2}{*}{5} & Rim creep (Yes/No) & Yes: 4 \\
\hline & & No: 6 \\
\hline \multirow[t]{2}{*}{6} & Collar fatigue (Yes/No) & Yes: 2 \\
\hline & & No: 8 \\
\hline \multirow[t]{2}{*}{7} & Grading of impingement according to Marchetti et al. [9] & Grade 0: 5 Grade 1: 1 \\
\hline & & Grade 2: 2 Grade 3: 2 \\
\hline
\end{tabular}

Two of them were PE liner with elevated rim, which the impingement site was both at the elevated and nonelevated part (Figures 3 and 4)

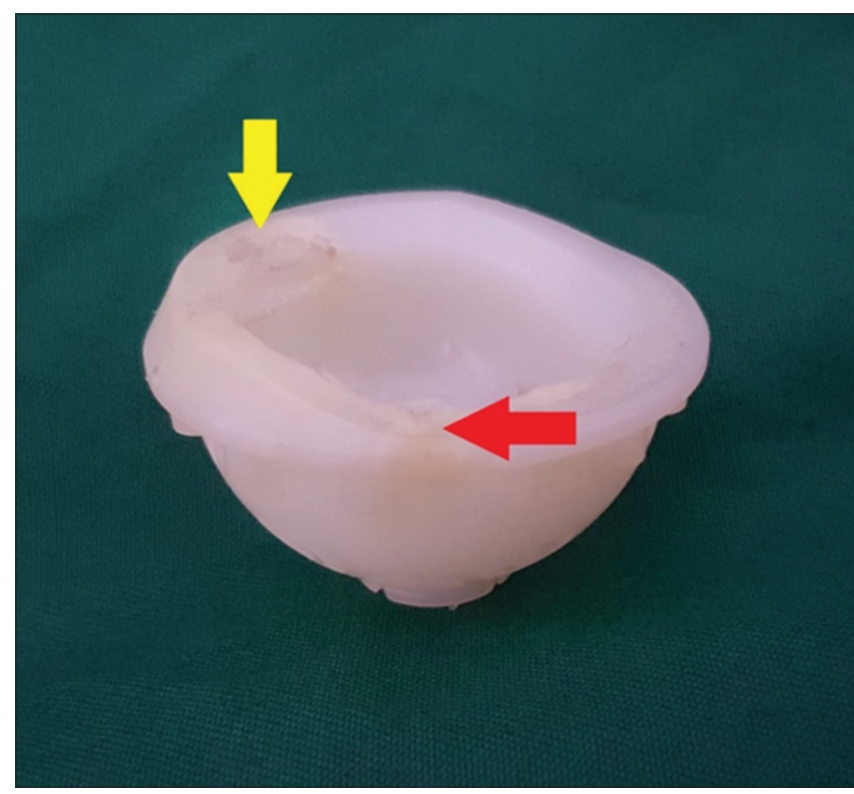

Figure 3: Impingement could occurred both on elevated (yellow arrow) and non-elevated part (red arrow) (Source: Author personal collection)

\section{Salat activity}

A Muslim person have to do prayer (Salat) 5 times a day which consist of several movements include standing (start), bowing (ruku'), straightening up (standing after bowing/i'tidal), prostrating (sujud), and sitting (tahiyat) [4], [13]. All those movements are sequenced in a raka'at (Figure 5). In one raka'at, there 

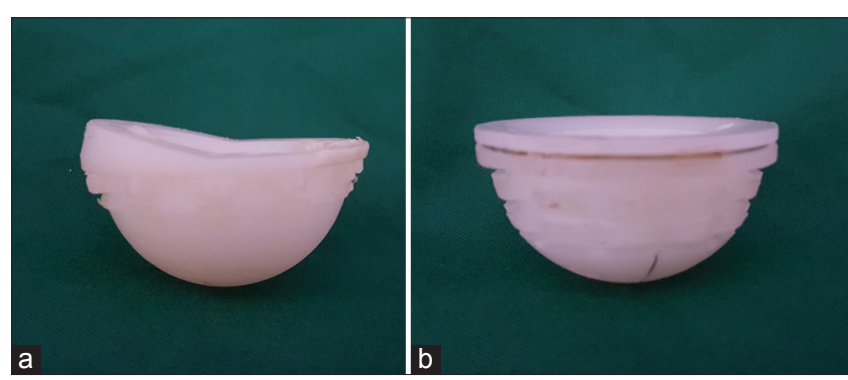

Figure 4: Different acetabular PE liner design with rim elevation (a) and without rim elevation/standard (b) (Source: Author personal collection)

are one standing (start), one bowing, one straightening up (standing), two prostration, and one sitting. In 1 day, a Muslim has to do Salat in totally 17 raka'at. Therefore, there will be a total of 17 times standing, 17 times bowing, 17 times straightening up, 34 times prostration, and 17 times sitting in a day (Table 4) [4], [14], [15].

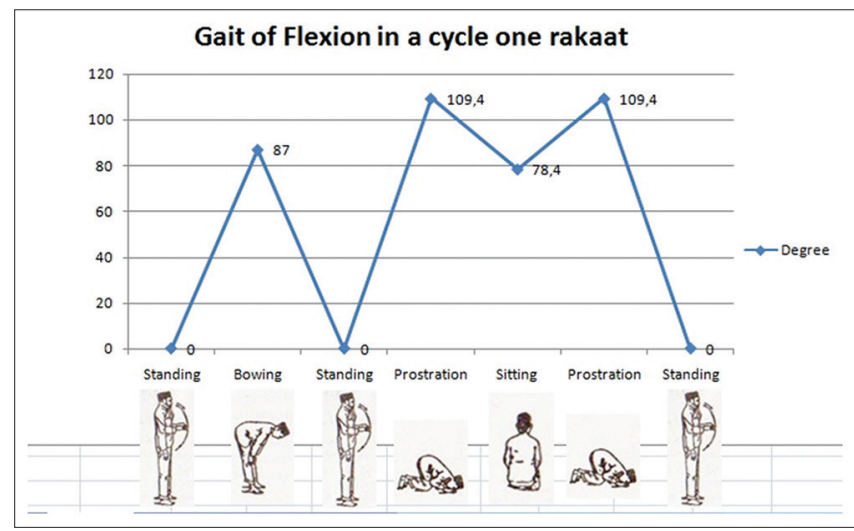

Figure 5: Sequence of hip joint movement (flexion) in Salat activity in one raka'at.15

There have been only few literature described the salat activity in correlation to impingement of THA prosthesis. A previous study by Jamari et al. [16] on simulation of hip joint movement during Salat activity showed that impingement of hip joint prosthesis could occur during three positions include sitting (tahiyat), prostration (sujud), and transition of standing toward prostration (Figure 6a and b) [16]. Impingement to the left hip during tahiyat sitting occurred as combination of hip flexion by $74.5^{\circ}$, abduction by $13.2^{\circ}$, and exorotation by $37.7^{\circ}$ (Figure $7 a-c$ ), while the transition of standing toward prostration resulted an impingement due to extreme flexion at $121.5^{\circ}[16]$.

Table 4: Range of hip joint movement (flexion) during Salat activity

\begin{tabular}{llll}
\hline $\begin{array}{l}\text { Movements in } \\
\text { Salat }\end{array}$ & \multicolumn{2}{l}{$\begin{array}{l}\text { Study by Ariff et al. [14] (mean and } \\
\text { range) }\end{array}$} & $\begin{array}{l}\text { Study by Towijaya et al. } \\
\text { [15] (maximum) }\end{array}$ \\
\cline { 2 - 3 } & Right & Left & \\
\hline Bowing (Ruku) & $74.1(60-85)$ & $74.3(56.3-86.7)$ & 87 \\
Sitting (Tahiyat) & $77.3(65-90)$ & $77.7(65-88.3)$ & 78.4 \\
Prostration (Sujud) & $118.1(91.7-138.3)$ & $119(95-140)$ & 109.4 \\
\hline
\end{tabular}

Another study involved a simulation test for repeated impingement of THA prosthesis during Salat activity. The result showed that the repetition of tahiyat sitting during salat movement induces repeated impingements and higher plastic deformation. The

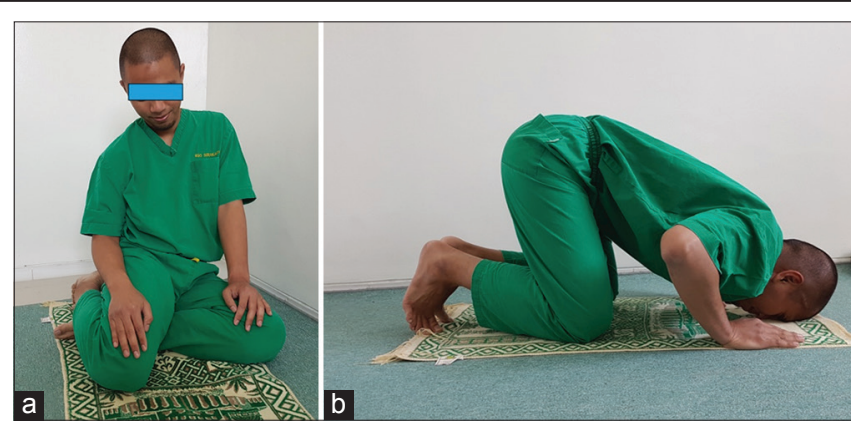

Figure 6: Tahiyat (sitting) position (a) and Sujud (prostration) (b) during Salat activity.

PE liner experiences dimensional change on the lip and has a potency to cause clinical failure of total hip replacement. A PE material with higher elastic moduli and lower in yield strength experiences higher plastic deformation and plastic strain than material with lower elastic moduli and higher in yield strength. The study suggested to make a new design of THA prosthesis to prevent impingement during salat activity; however, no specific point has been suggested about the design [17].
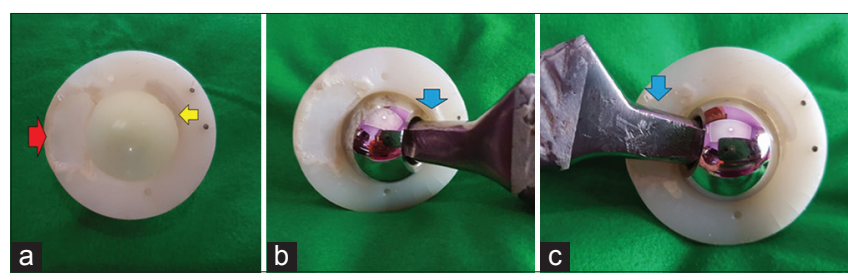

Figure 7: (a) Impingement occurred at different site at one PE liner (b) Impingement at superolateral site possibly associated with hip flexion, abduction and external rotation (Tahiyat sitting for left hip), (c) Impingement at inferomedial site possibly associated with flexion, adduction and internal rotation of hip joint. (Source: Author personal collection)

Further study by Ismail et al. [18] suggested several point to consider in the making of the new design of artificial hip joint model which allows THA patients to perform salat in a normal manner. The reduction of inset at the liner, the new profile at circumferential edge inner liner, and the increase in the femoral head diameter were advised as a guideline for new design of the artificial hip joint for Muslim [18].

\section{Consideration to Prevent Impingement in Salat Activity}

The first classic factor to consider to prevent impingement is implant position. The acceptable (safe zone) acetabular cup orientation has been described by Lewinnek et al. [19]. They recommend $40^{\circ}\left( \pm 10^{\circ}\right)$ of inclination and $15^{\circ}\left( \pm 10^{\circ}\right)$ of anteversion. Cups placed outside this "safe zone" had an increased dislocation risk by 4 times compared to control group. However, a recent study by Tezuka et al. [20] showed that the concept of "functional safe zone" is better to predict stability after 
THA compared to the Lewinnek safe zone. They found that $14.2 \%$ of prosthesis within the Lewinnek's zone were not in the functional safe zone, this gives a potential for prosthesis dislocation despite having "normal" cup position. A biomechanical study by Elkins et al. [21] showed that a cup placed more horizontal could induce prosthesis impingement during squatting. The squatting position is almost similar to "transition movement from standing toward prostration" which has been revealed as one of the high-risk movements in Salat activity [16]. Therefore, a more horizontal cup position maybe has to be avoided for Muslim population. Consideration of femoral stem position also important in order to prevent prosthesis impingement. A study by Renkawitz et al. [22] investigates the effect of femoral stem tilt (FT) to the risk of implant impingement of THA. They found that the FT has a significant impact on recommended cup positions within the concept of "femur first" or "combined anteversion." Ignoring FT may pose an increased risk of impingement as well as dislocation. Therefore, a further study to define "special safe zone" including the cup and femoral position of THA implant is needed for Muslim population to prevent impingement and dislocation during Salat activity. Furthermore, to increase the accuracy on implant placement, the use of navigation system also might be considered [23]. A recent study by Palit et al. [24] showed that the use of computer navigation system could significantly reduce impingement severity both on bone-to-bone and implant-to-implant impingement compared to conventional group [24].

Larger head diameter could reduce the risk of prosthesis impingement [8]. Several previous studies have been proved the benefit of using larger femoral head diameter. A study by Zijlstra et al. [25] revealed that there was a benefit in using $32 \mathrm{~mm}$ heads instead of 22-28 $\mathrm{mm}$ heads, regardless the type of surgical approach. They also found that the use of head diameter of $\geq 36 \mathrm{~mm}$ showed to significantly reduce the risk of dislocation in posterolateral approach [25]. Another study by Plate et al. [26] found no case of dislocation after THA with anterolateral approach when using $\geq 36 \mathrm{~mm}$ head diameter. Conversely, dislocation occurred at $3.8 \%$ of cases when using $<36 \mathrm{~mm}$ head diameter. Although further study also still needed, we may recommend to use $a \geq 36 \mathrm{~mm}$ of head diameter for THA in Muslim population.

The last consideration is to modify the Salat movement itself. The religion of Islam allows the Muslim person to modify some of the Salat movement in special circumstances include sickness, disabled condition, or other morbidity high-risk conditions. The safest way to prevent impingement and dislocation is to advice the patient who received THA to perform Salat with "sitting on the chair" without prostration and tahiyat sitting, which it is allowed in the religion of Islam. Unfortunately, not all patients obey the advice, as some still wanted to perform Salat in the original manner to follow their believe.

\section{Summary}

Prosthesis impingement is an important event that could alter the outcome of THA. The potential impingement positions during Salat activity have been revealed by the previous computer simulation study, some evidences of impingement from retrieved PE liner also have been showed from our recent preliminary data. Some consideration to prevent prosthesis impingement from implant choice and position also modification of Salat movement has been described in this review, although further study is needed in this field.

\section{References}

1. Soong M, Rubash HE, Macaulay W. Dislocation after total hip arthroplasty. J Am Acad Orthop Surg. 2004;12(5):314-21. https://doi.org/10.5435/00124635-200409000-00006 PMid:15469226

2. Khatod M, Barber T, Paxton E, Namba R, Fithian D. An analysis of the risk of hip dislocation with a contemporary total joint registry. Clin Orthop Relat Res. 2006;447:19-23. https://doi. org/10.1097/01.blo.0000218752.22613.78

PMid:16741469

3. Zahar A, Rastogi A, Kendoff D. Dislocation after total hip arthroplasty. Curr Rev Musculoskelet Med. 2013;6(4):350-6. https://doi.org/10.1007/s12178-013-9187-6

PMid:24170479

4. Dudda M, Gueleryuez A, Gautier E, Busato A, Roeder C. Risk factors for early dislocation after total hip arthroplasty: A matched case-control study. J Orthop Surg (Hong Kong). 2010;18(2):17983. https://doi.org/10.1177/230949901001800209 PMid:20808008

5. Cinotti G, Lucioli N, Malagoli A, Calderoli C, Cassese F. Do large femoral heads reduce the risks of impingement in total hip arthroplasty with optimal and non-optimal cup positioning? Int Orthop. 2011;35(3):317-23. https://doi.org/10.1007/ s00264-010-0954-3

PMid:20157813

6. Sheikh A, Gatrad AR, editors. Caring for Muslim Patients. $2^{\text {nd }}$ ed Oxford: Radcliffe; 2007.

7. Brown TD, Elkins JM, Pedersen DR, Callaghan JJ. Impingement and dislocation in total hip arthroplasty: Mechanisms and consequences. lowa Orthop J. 2014;34:1-15

PMid:25328453

8. Malik A, Maheshwari A, Dorr LD. Impingement with total hip replacement. J Bone Joint Surg Am. 2007;89(8):1832-42. https://doi.org/10.2106/jbjs.f.01313

PMid:17671025

9. Marchetti E, Krantz N, Berton C, Bocquet D, Fouilleron N Migaud $\mathrm{H}$, et al. Component impingement in total hip arthroplasty: Frequency and risk factors. A continuous retrieval analysis series of 416 cup. Orthop Traumatol Surg Res. 2011;97(2):127-33. https://doi.org/10.1016/j.otsr.2010.12.004 PMid:21377948

10. Mueller U, Lee C, Heisel C, Thomsen M, Bitsch RG, Kretzer JP. Failure of polyethylene inlays in cementless total hip arthroplasty: A retrieval analysis. Biomed Res Int. 2016;2016:1-7. https://doi. 
org/10.1155/2016/5496396

11. French $\mathrm{K}$, Moore R, Gawel H, Kurtz SM, Kraay MJ, Xie K, et al. Retrieval analysis of Harris-Galante I and II acetabular liners in situ for more than 10 years. Acta Orthop. 2012;83(4):366-73. https://doi.org/10.3109/17453674.2012.717843 PMid:22880709

12. Tanino H, Harman MK, Banks SA, Hodge WA. Association between dislocation, impingement, and articular geometry in retrieved acetabular polyethylene cups. J Orthop Res. 2007;25(11):1401-7. https://doi.org/10.1002/jor.20410 PMid: 17471491

13. Hussain $W$, Hussain $H$, Hussain $M$, Hussain $S$, Attar $S$. Approaching the Muslim orthopaedic patient. J Bone Joint Surg Am. 2010;92(7):e2. https://doi.org/10.2106/jbjs.j.00065 PMid:20595558

14. Ariff MS, Arshad AA, Johari MH, Affandi MA, Fadzli AS, Ashikin NT, et al. The study on range of motion of hip and knee in prayer by adult Muslim males. A preliminary report. Int Med J Malaysia 2015;14(1):49-58.

15. Towijaya $T$, Ismail $R$, Jamari J. Design of a hip prosthetic tribometer based on salat gait cycle. AIP Conf Proc. 2017;1788:30071. https://doi.org/10.1063/1.4968324

16. Jamari J, Anwar IB, Saputra E, van der Heide E. Range of motion simulation of hip joint movement during salat activity. J Arthroplasty. 2017;32(9):2898-904. https://doi.org/10.1016/j. arth.2017.03.056

PMid:28499625

17. Jamari J, Ismail R, Saputra E, Sugiyanto S, Anwar IB. The effect of repeated impingement on UHMWPE material in artificial hip joint during salat activities. Adv Mater Res. 2014;896:272-5. https://doi.org/10.4028/www.scientific.net/amr.896.272

18. Ismail R, Saputra E, Tauviqirrahman M, Legowo AB, Anwar IB, Jamari J. Numerical study of salat movements for total hip replacement patient. Appl Mech Mater. 2014;493:426-31. https://doi.org/10.4028/www.scientific.net/amm.493.426

19. Lewinnek GE, Lewis JL, Tarr R, Compere CL, Zimmerman JR. Dislocations after total hip replacement arthroplasties. J Bone Joint Surg Am. 1978;60(2):217-20. https://doi. org/10.2106/00004623-197860020-00014

PMid:641088

20. Tezuka T, Heckmann ND, Bodner RJ, Dorr LD. Functional safe zone is superior to the lewinnek safe zone for total hip arthroplasty: Why the lewinnek safe zone is not always predictive of stability. J Arthroplasty. 2019;34(1):3-8. https://doi. org/10.1016/j.arth.2018.10.034

PMid:30454867

21. Elkins JM, Pedersen DR, Callaghan JJ, Brown TD. Boneon-bone versus hardware impingement in total hips: A biomechanical study. lowa Orthop J. 2012;32:17-21. PMid:23576916

22. Renkawitz T, Haimerl M, Dohmen L, Gneiting S, Lechler $P$, Woerner $\mathrm{M}$, et al. The association between femoral tilt and impingement-free range-of-motion in total hip arthroplasty. BMC Musculoskelet Disord. 2012;13:65. https://doi. org/10.1186/1471-2474-13-65

PMid:22559740

23. Davenport D, Kavarthapu V. Computer navigation of the acetabular component in total hip arthroplasty: A narrative review. EFORT Open Rev. 2016;1(7):279-85. https://doi. org/10.1302/2058-5241.1.000050 PMid:28670481

24. Palit A, Williams MA, Turley GA, Renkawitz T, Weber M. Femur first navigation can reduce impingement severity compared to traditional free hand total hip arthroplasty. Sci Rep. 2017;7(1):7238. https://doi.org/10.1038/s41598-017-07644-4

25. Zijlstra WP, De Hartog B, Van Steenbergen LN, Scheurs BW, Nelissen RG. Effect of femoral head size and surgical approach on risk of revision for dislocation after total hip arthroplasty. Acta Orthop. 2017;88(4):395-401. https://doi.org/10.1080/17453674. 2017.1317515

PMid:28440704

26. Plate JF, Seyler TM, Stroh DA, Issa K, Akbar M, Mont MA. Risk of dislocation using large-vs. Small-diameter femoral heads in total hip arthroplasty. BMC Res Notes. 2012;5:553. https://doi. org/10.1186/1756-0500-5-553

PMid:23039109 